\title{
Pharmacokinetics of continuous transarterial infusion of 5-fluorouracil in patients with advanced hepatocellular carcinoma
}

\author{
JIAN GAO $^{1}$, RUI ZHEN ${ }^{1}$, HAI LIAO ${ }^{2}$, WENQUAN ZHUANG ${ }^{1}$ and WENBO GUO ${ }^{1}$ \\ ${ }^{1}$ Department of Interventional Radiology, The First Affiliated Hospital of Sun Yat-sen University; ${ }^{2}$ Department of \\ Clinical Trials and Research on Cancer, Sun Yat-sen University Cancer Center, Guangzhou, Guangdong 510080, P.R. China
}

Received September 22, 2017; Accepted February 23, 2018

DOI: $10.3892 / \mathrm{ol} .2018 .8242$

\begin{abstract}
Numerous studies concerning hepatic arterial infusion chemotherapy (HAIC) have been conducted by adopting regimens containing 5-fluorouracil (FU), with a favourable efficacy compared with conventional transcatheter arterial chemoembolisation (TACE) treatment; however, the detailed mechanism of HAIC remains unclear. The present study aimed to evaluate peripheral concentration time curves of 5-FU administered through the hepatic artery, which may additionally explain the mechanism of action of HAIC. A total of 10 eligible patients underwent transcatheter arterial embolization and a 2-day HAIC treatment regimen using a folinic acid, fluorouracil and oxaliplatin regimen. Peripheral venous blood sampling was performed in each patient prior to infusion, and at $0,0.5,1,1.5,2,5,10,15,22$ and $23 \mathrm{~h}$ following the start of infusion. The blood sample at $0 \mathrm{~h}$ was analysed for dihydropyrimidine dehydrogenase (DPD) levels by high performance liquid chromatography, and the rest of the samples were analysed for 5-FU by optimised liquid chromatography-mass spectrometry (LC-MS). The lower limit of quantification of optimised LC-MS for $5-\mathrm{FU}$ was $5 \mathrm{ng} / \mathrm{ml}$. The steady-state plasma concentration of 5-FU administered through the hepatic artery was achieved after $15 \mathrm{~h}$. This concentration largely varied, ranging from $8.64-152.00 \mathrm{ng} / \mathrm{ml}$. Optimised LC-MS may detect low concentrations of 5-FU. The steady-state concentration of 5-FU administered through the hepatic artery was achieved after $15 \mathrm{~h}$. DPD levels were analysed through determining the ratio of plasma uracil (U) and dihydrouracil (UH2) by HPLC, and the results indicated a mild DPD deficiency in the patients with HCC. These results
\end{abstract}

Correspondence to: Professor Wenbo Guo, Department of Interventional Radiology, The First Affiliated Hospital of Sun Yat-sen University, 58 Zhongshan 2nd Road, Guangzhou, Guangdong 510080, P.R. China

E-mail: patrickguo2008@163.com

Key words: hepatocellular carcinoma, hepatic arterial infusion chemotherapy, transcatheter arterial chemoembolisation, folinic acid, fluorouracil and oxaliplatin treatment, 5-fluorouracil may provide a basis for the explanation of the clinical efficacy of HAIC, and to additionally optimise its efficacy.

\section{Introduction}

Transcatheter arterial chemoembolisation (TACE) is recommended by the American Association for the Study of Liver Disease as the first-line treatment for unresectable hepatocellular carcinoma (HCC) (1), and is widely performed in clinical practice due to its favourable efficacy compared with conservative medical management or systematic treatment (2-4) and minimal invasion. However, the survival benefit following TACE remains limited (2). The present study reviewed the literature and revealed that TACE, combined with hepatic arterial infusion chemotherapy (HAIC), may achieve significantly longer progression-free survival (PFS) times (8.0-9.3 months) compared with patients treated with TACE alone (PFS, 4.5 months) $(5,6)$. Presumably due to technical refinements in HAIC protocol, no bleeding, thrombus, infection or other associated complications caused by the indwelling catheter in the HAIC procedure were identified in recent studies $(6,7)$, suggesting that continuous transarterial infusion of 5-fluorouracil (5-FU) is a generally safe treatment, and it is more effective compared with TACE alone for patients with advanced HCC.

However, the underlying cause of the improving efficacy of HAIC remains unclear. It appears that the primary difference between TACE and TACE + HAIC is the approach of administrating chemotherapeutic agents: TACE is administered via bolus and HAIC is administered via a prolonged, continuous infusion (8). Theoretically, the prolonged, high regional concentration of the chemotherapeutic agent at the tumour site would be expected to increase anti-tumour effects in HAIC, particularly for time- and concentration-dependent agents $(9,10) ; 5$-FU was one of these time-dependent drugs (9).

5 -FU was introduced as an anti-tumour drug in the 1950s (11) and it remains the primary agent of various chemotherapy regimens. However, the metabolism of 5-FU largely differs among individuals depending on age (12), sex $(12,13)$ and hepatic insufficiency due to HCC and gene polymorphisms in the dihydropyrimidine dehydrogenase gene (DPYD), which encodes DPD and is involved in the catabolism of 5-FU (14-16). Despite this, in previous studies, HAIC using regimens containing 5-FU was performed with favourable efficacy compared with conventional TACE or best supportive 
care (17-19). Due to the clinical efficacy of HAIC and individual variation of 5-FU described above, the present study aimed to explore more detailed associations, and to additionally explain the improved efficacy achieved by HAIC. However, studies on the pharmaceutics of transarterial 5-FU infusions are lacking, particularly in patients with advanced HCC and hypohepatia, which limits additional investigation. Therefore, the present study was initiated to evaluate the peripheral concentration time curves of 5-FU administrated through the hepatic artery, to provide an explanation of its clinical efficacy and a basis for optimization of this efficacy.

\section{Materials and methods}

Patient characteristics. The present study was conducted in the First Affiliated Hospital of Sun Yat-Sen University (Guangzhou, China). The primary eligibility criteria included patients with histologically-confirmed (20) HCC with an Eastern Cooperative Oncology Group performance status (21) of $\leq 2$, those with a Child-Pugh score (22) A, those with Barcelona Clinic liver cancer stage C (23) and those receiving 2 days of continuous HAIC following conventional TACE. The primary exclusion criteria included patients with severe coronary heart disease, those with severe active infection [ $>$ grade 2, National Cancer Institute Common Terminology Criteria for Adverse Events v4.0 criteria (24)], those with HIV infection, those with renal insufficiency (creatinine level $>2 \mathrm{mg} / \mathrm{dl}$ ) or those with allergies to platinum compounds, 5-FU or contrast media. All patients provided written informed consent. The present study was approved by the First Affiliated Hospital of Sun Yat-sen University Ethics Committee. Baseline evaluation included the maximal diameter measurement of viable tumours using dynamic contrast-enhanced computed tomography according to the modified Response Evaluation Criteria in Solid Tumours criteria (25) and biochemical examination such as levels of $\alpha$-fetoprotein, albumin, bilirubin, alanine aminotransferase, aspartate transaminase, status of hepatitis B virus and hepatitis $\mathrm{C}$ virus infection and prothrombin time.

Treatment protocol. A total of 10 patients totally underwent 18 cycles of TACE + HAIC. The duration of each TACE + HAIC cycle was 3 days, with a hospital stay ranging from 8 to 12 days. The interval between each cycle was 3 weeks. All patients underwent a 2-day HAIC treatment regimen using a folinic acid, fluorouracil and oxaliplatin (FOLFOX4) regimen: $85 \mathrm{mg} / \mathrm{m}^{2}$ oxaliplatin (Eloxatin ${ }^{\circledR}$; Sanofi S.A., Paris, France) for $2 \mathrm{~h}$ on day 1; $200 \mathrm{mg} / \mathrm{m}^{2}$ leucovorin (Lingnan Pharmaceutical, Ltd., Guangdong, China) for $2 \mathrm{~h}$ on days 1 and 2; $400 \mathrm{mg} / \mathrm{m}^{2}$ 5-FU (Sinochem Group, Beijing, China) bolus on days 1 and 2 ; and $600 \mathrm{mg} / \mathrm{m}^{2} 5$-FU on days 1 and 2, via an ambulatory infusion pump (MR-508; Zhuhai MeiRuiHua Medical Technology Co., Ltd., Guangdong, China) following conventional TACE. TACE and HAIC were performed as mentioned below.

A 5-F catheter was inserted into the femoral artery using the Seldinger technique (26) following routine preoperative preparation including fasting for $6 \mathrm{~h}$ and pubic hair removal. Arteriography of the celiac trunk and hepatic and superior mesenteric arteries was performed to visualise the arterial vascularisation of the tumour and to evaluate portal vein patency, respectively. Guided by fluoroscopy, the tip of the catheter, or microcatheter if necessary, was superselected into the tumour-feeding branches using a guidewire. The embolisation of target tumour-feeding vessels was performed by injecting a gelatine sponge [Nanjing Jingling Pharmaceutical (Group) Co., Ltd., Nanjing, China] or polyvinyl alcohol particles (Hangzhou Alicon Pharmaceutical SCI\&TEC Co., Ltd., Hangzhou, China). Following embolisation, the catheter was inserted and the patient was returned to the ward for FOLFOX4 administration. Regular analgesia (Tramadol, $0.1 \mathrm{~g}$ intramuscularly, Hexal AG, Holzkirchen, Germany) and nausea-controlling drugs (Palonosetron, $0.25 \mathrm{mg}$ intravenously; Qilu Pharmaceutical Co., Ltd., Jinan, China) were administered during the HAIC. As soon as consecutive transarterial FOLFOX4 treatment was finished, the catheter was removed, the puncture site was stanched by compression for $\sim 15$ min and pressure bandaging was applied.

Pharmacokinetic blood sampling. A total of 11 peripheral venous blood samplings were collected from all 10 patients, and each contained $3 \mathrm{ml}$ blood from prior the infusion at admission and at $0,0.5,1,1.5,2,5,10,15,22$ and $23 \mathrm{~h}$ following the initiation of infusion on day 1 . Immediately after drawing, blood samples were centrifuged at room temperature at $1,118.0 \mathrm{x} \mathrm{g}$ for $10 \mathrm{~min}$, and the supernatant was stored in clean $1.5 \mathrm{ml}$ polypropylene tubes and stored at $-80^{\circ} \mathrm{C}$.

Optimising the extraction method and liquid chromatography-mass spectrometry (LC-MS) conditions. The extraction method described by Remaud et al (27) was simplified by removing the evaporation procedure. Firstly, $100 \mathrm{mg}$ ammonium sulfate was added into $100 \mu \mathrm{l}$ plasma samples to precipitate plasma proteins. Following vortex mixing at $50.31 \mathrm{x} g$ at room temperature for $1 \mathrm{~min}, 300 \mu \mathrm{l}$ internal standard (IS) solution (5-Br; Sigma-Aldrich; Merck KGaA, Darmstadt, Germany) was added. The samples were gently mixed at room temperature for $1 \mathrm{~min}$ in a rotary stirrer (45 rotations/min) and centrifuged for $10 \mathrm{~min}$ at $25,758.7 \mathrm{x} \mathrm{g}$ and $4^{\circ} \mathrm{C}$. A total of $100 \mu \mathrm{l}$ supernatant was then transferred to an autosampler vial prior to injection onto the column. Volume injection was set at $20 \mu \mathrm{l}$ for 5-FU and 5-bromopyrimidine (5-Br).

The standard curve of 5-FU was prepared by adding $20 \mu \mathrm{l}$ standard solution $(50 \mu \mathrm{g} / \mathrm{ml})$ of industrial pure 5-FU (provided by National Institute for Food and Drug Control, Beijing, China) and $10 \mu \mathrm{l}$ IS (5-Br) to $980 \mu \mathrm{l}$ control human plasma. IS concentration was set at $50 \mathrm{ng} / \mathrm{ml}$. Final generated concentrations were 10, 20, 50, 200, 600 and $1,000 \mathrm{ng} / \mathrm{ml}$ for 5 -FU. Quality controls of 10,30 and $100 \mathrm{ng} / \mathrm{ml}$ of 5-FU were considered low, moderate and high concentrations, respectively, and used to verify the standard curve delineated by $10,20,50,200$, 600 and $1,000 \mathrm{ng} / \mathrm{ml} 5$-FU. All samples were then treated according to the extraction method and high-performance liquid chromatography (HPLC) at room temperature as follows. Standard curves for 5-FU were generated by plotting the peak area ratio to that of the IS vs. the concentration of each compound.

Notably, unlike LC conditions in previous studies (27-33), the mobile phase solvent $\mathrm{A}$ in the present study contained $0.1 \%$ $(\mathrm{v} / \mathrm{v})$ formic acid in water, and the mobile phase solvent B contained $100 \%$ acetonitrile. The mobile phase composition 
Table I. Liquid chromatography mass spectrometry system information.

\begin{tabular}{|c|c|c|}
\hline Instrument & Version & Supplier \\
\hline Mass spectrometer & AB Sciex API 2000 & AB Sciex Pte. Ltd., Warrington, UK \\
\hline Liquid chromatography system & Agilent Technologies 1200 series & $\begin{array}{l}\text { Agilent Technologies, Inc., Santa Clara, } \\
\text { CA, USA }\end{array}$ \\
\hline Chromatographic column & $\begin{array}{l}\text { Agilent Eclipse XDB-C18, } 4.6 \times 150 \mathrm{~mm} \text {, } \\
5 \mu \mathrm{m}\end{array}$ & $\begin{array}{l}\text { Agilent Technologies, Inc., Santa Clara, } \\
\text { CA, USA }\end{array}$ \\
\hline Data acquisition and analysis system & Analyst 1.6, AB Sciex & AB Sciex Pte. Ltd., Warrington, UK \\
\hline
\end{tabular}

was $5 \%$ solvent $\mathrm{A}$ and $95 \%$ solvent $\mathrm{B}$, which was pumped at a flow rate of $380 \mu \mathrm{l} / \mathrm{min}$ for $10 \mathrm{~min}$. Other parameters are summarised in Tables I and II.

DPD levels were also analysed in this research. Direct approaches of determining DPD, such as genotyping, quantification of DPD mRNA have been proved cumbersome to realise $(16,34)$. An alternative method by measuring the ratio of plasma uracil (U) and dihydrouracil (UH2) through HPLC was adopted in this research as DPD is responsible for catabolism of $\mathrm{U}$ to $\mathrm{UH} 2(35,36)$. Elevated ratios ( $\mathrm{U}: \mathrm{UH} 2>2$ ) have been reported highly correlated to DPD deficiency (37-40).

\section{Results}

Prior to receiving the results, it was hypothesised that the steady-state concentration of 5-FU would range between 200-300 ng/ml, due to previous data from studies examining colorectal cancer (41-43).

Baseline characteristics of 10 patients are summarised in Table III. Representative chromatograms and linearity of 5-FU added into control plasma are presented in Figs. 1 and 2. Plasma concentration vs. time curves of 5-FU are illustrated in Fig. 3 and detailed information is summarised in Table IV. At $0 \mathrm{~h}$ of continuous infusion of 5-FU, the plasma concentration of 5-FU was markedly high compared with the normal range $(200-300 \mathrm{ng} / \mathrm{ml})$ due to previous 5-FU bolus; this concentration rapidly decreased to relatively normal levels within $2 \mathrm{~h}$ and then fluctuated mildly to reach a steady state. According to Fig. 3, a steady-state plasma concentration of 5-FU, administered through the hepatic artery, was achieved after $15 \mathrm{~h}$; this concentration widely varied in the 10 patients, ranging from $8.64-152 \mathrm{ng} / \mathrm{ml}$. The ratio of U and UH2 (U:UH2) fluctuated from 1.98-2.06, indicating mild DPD deficiency in these 10 patients with HCC.

\section{Discussion}

To the best of our knowledge, this is the first study to quantitatively evaluate plasma concentration time curves of 5-FU continuously administered through the hepatic artery for $>44 \mathrm{~h}$ in patients with advanced HCC. As the therapeutic agent first passes through the liver in HAIC, which is the organ involved in its eventual metabolism, lower peripheral blood concentration and fewer systemic side effects are anticipated (8). A conventional HPLC was not used, as the lower limit of quantification (LLOQ) was $100 \mathrm{ng} / \mathrm{ml}(44,45)$, and thus it may not detect lower concentrations of 5-FU in
Table II. Mass spectrometer settings for the analysis of 5-fluoruracil in human plasma.

\begin{tabular}{lc}
\hline Detector parameters & Setting \\
\hline Ion source & Electrospray ionization \\
Ionization modes & Negative \\
Scanning mode & Multiple reaction \\
& monitoring scanning \\
Selected reaction monitoring & $5-\mathrm{FU}: 129.0 \rightarrow 42.1 ;$ \\
transition & $5-\mathrm{Br}: 188.9 \rightarrow 52.0$ \\
De-clustering potential & $-20 \mathrm{~V}$ \\
Focusing potential & $-400 \mathrm{~V}$ \\
Entrance potential & $-10 \mathrm{~V}$ \\
Collision energy & $-18 \mathrm{~V}$ \\
Collision cell exit potential & $-5 \mathrm{~V}$ \\
Curtain gas & $20 \mathrm{TSI}$ \\
Collision gas & 8 \\
Ion spray gas & $-4500 \mathrm{~V}$ \\
Temperature & $400^{\circ} \mathrm{C}$ \\
Ion source gas 1 & $55 \mathrm{PSI}$ \\
Ion source gas 2 & $50 \mathrm{PSI}$ \\
Flow rate & $380 \mu 1 / \mathrm{min}$ \\
\hline
\end{tabular}

$\mathrm{V}$, volts; PSI, pound per square inch.

peripheral blood during HAIC. A more sensitive method with an LLOQ of 5-10 $\mathrm{ng} / \mathrm{ml}$ was identified from previous studies $(27,31-33,46)$, and the procedure was simplified to meet clinical requirements. It should be noted that specific parameters, primarily the aforementioned LC conditions, of the LC-MS performed in the present study were not exactly the same in different centres with different instruments when the methods published previously were repeated (27-33). The results of the present study suggest that 5-FU was better extracted by precipitate plasma proteins with ammonium sulfate compared with simple liquid-liquid extraction with acetonitrile or formic acid in acetonitrile. Additionally, with the evaporation procedure, the ultimate peak intensity may be more marked compared with any other procedure, but took a longer time. For clinical application, the evaporation process was removed.

The half-life of 5-FU in the human body is 10-20 min (47). The majority of drugs will reach steady state following 


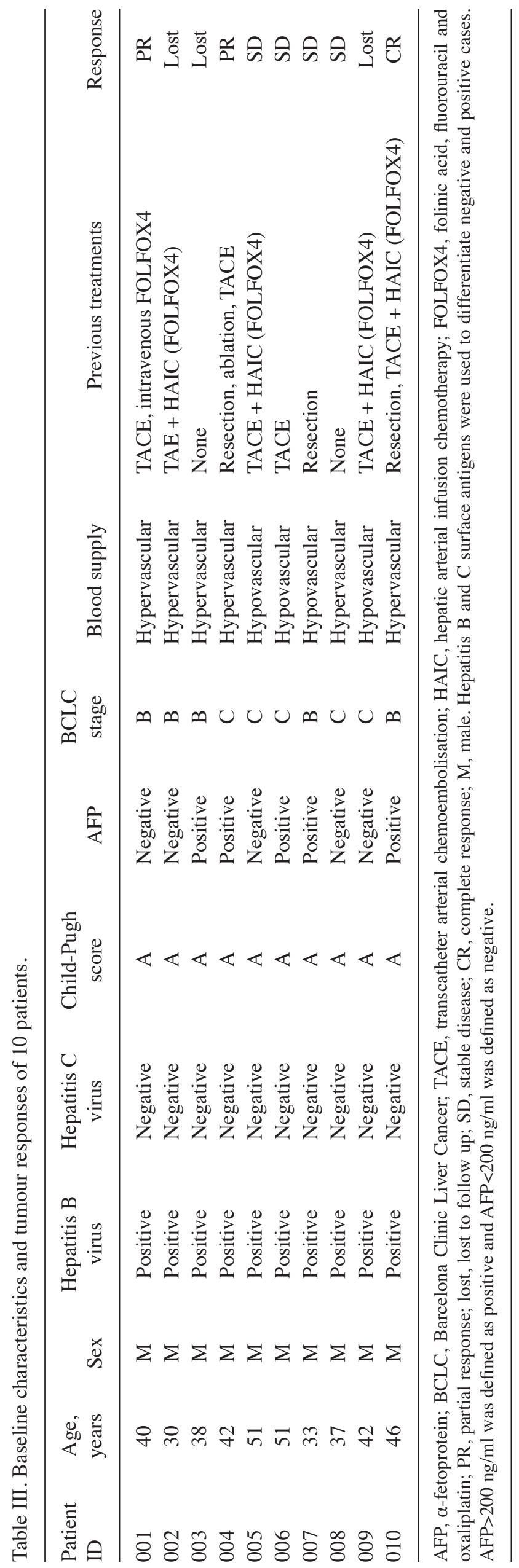

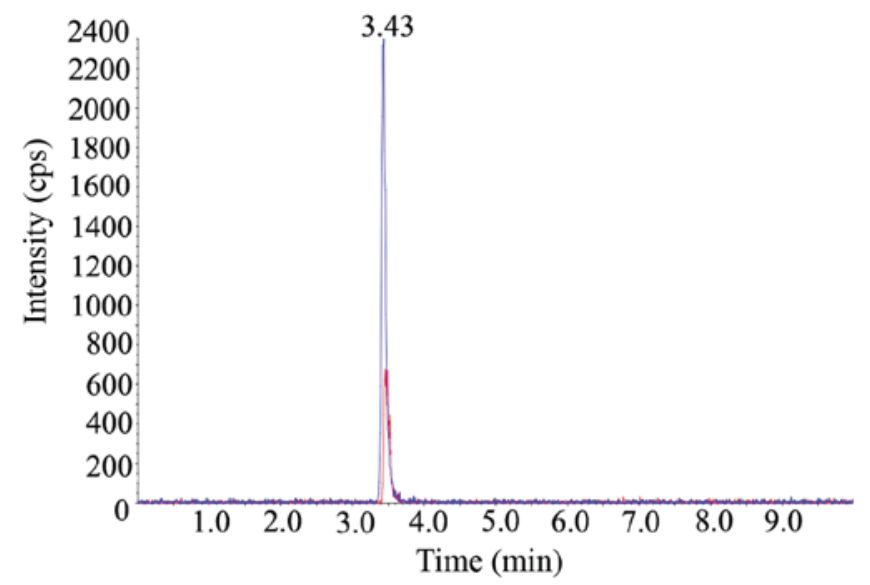

Figure 1. 5-FU and 5-Br extracted from blood plasma. The concentration of 5 -FU and $5-\mathrm{Br}$ were $500 \mathrm{ng} / \mathrm{ml}$. The blue peak represents 5 -FU, with a retain time of $3.43 \mathrm{~min}$ (peak summit) and intensity of 2,300 cps. The red peak represents $5-\mathrm{Br}$, with retain time of $3.50 \mathrm{~min}$ and intensity of $680 \mathrm{cps}$. 5-FU, 5-fluoruracil; 5-Br, 5-bromopyrimidine.

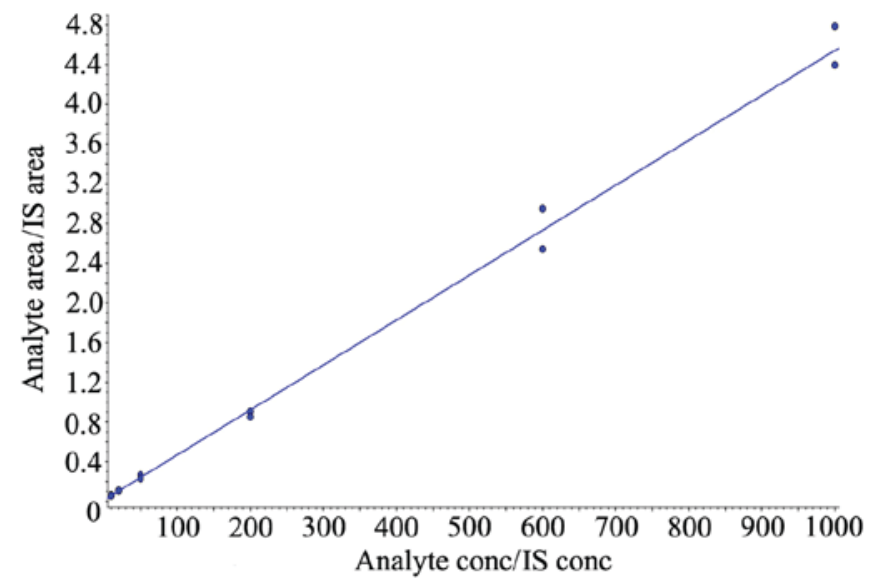

Figure 2. Linearity of 5-FU concentration. Standard curve of 5-FU was depicted according to concentrations of $10,20,50,200,600,1,000 \mathrm{ng} / \mathrm{ml}$ and the liner regression coefficient was 0.9966. $y=0.00453 x+0.0152(r=0.9966)$. 5-FU, 5-fluoruracil; IS, internal standard.

5 half-lives during continuous intravenous administration (48). In the present study, a steady-state plasma concentration of 5 -FU was achieved after $15 \mathrm{~h}$, which is much longer compared with the 5 half-lives of 5-FU. This conclusion was consistent with results obtained by Kaldate et al (49), which revealed that more factors than half-life alone affect the steady-state plasma concentration of 5-FU, particularly in patients with levels of liver dysfunction, including HCC. For additional studies on the steady-state concentration of 5-FU in peripheral blood and the efficacy of TACE + HAIC, the average time-points of 15 and $22 \mathrm{~h}$ are recommend for the measurement of the steady-state plasma concentration.

Notably,despite the mildfluctuation of U:UH2 from 1.98-2.06 in the 10 patients, the steady-state concentration of 5-FU varied widely between patients, ranging from 8.64-152 $\mathrm{ng} / \mathrm{ml}$, which indicates that factors separate from DPD levels require consideration. Concurrently, the steady-state concentration of 5-FU $(30.2-152.9 \mathrm{ng} / \mathrm{ml})$ in the present study was under the established therapeutic range, when administered venously, was 
Table IV. Detail information of 5-FU and DPD levels of 10 patients.

5-FU levels (ng/ml)

\begin{tabular}{lrrrrrrrrrrr} 
& \multicolumn{1}{c}{$0 \mathrm{~h}$} & $0.5 \mathrm{~h}$ & $1 \mathrm{~h}$ & $1.5 \mathrm{~h}$ & $2 \mathrm{~h}$ & $5 \mathrm{~h}$ & $10 \mathrm{~h}$ & $15 \mathrm{~h}$ & $22 \mathrm{~h}$ & $23 \mathrm{~h}$ & $\begin{array}{r}\text { infusion at } \\
\text { admission) }\end{array}$ \\
\cline { 2 - 9 } 001 & $12,477.0$ & $1,771.0$ & 336.1 & 106.6 & 128.3 & 114.3 & 94.7 & 88.4 & 148.7 & 0.0 & 2.02 \\
002 & $10,118.9$ & 237.1 & 102.4 & 74.8 & 62.5 & 54.9 & 55.8 & 54.1 & 62.8 & 44.7 & 2.05 \\
003 & $11,452.4$ & $1,150.8$ & 291.4 & 93.9 & 87.5 & 84.5 & 87.9 & 91.4 & 57.8 & 41.2 & 2.02 \\
004 & $2,200.0$ & 219.0 & 123.0 & 115.0 & 108.0 & 139.0 & 124.0 & 118.0 & 90.1 & 0.0 & 2.08 \\
005 & $6,390,000.0$ & 963.0 & 178.0 & 110.0 & 86.8 & 57.5 & 67.1 & 76.3 & 55.7 & 121.0 & 1.98 \\
006 & $1,650,000.0$ & 169.0 & 57.4 & 83.1 & 83.8 & 75.8 & 64.6 & 56.3 & 65.8 & 49.4 & 2.00 \\
007 & $10,500.0$ & 508.0 & 46.7 & 36.1 & 33.3 & 35.4 & 8.6 & 30.2 & 35.8 & 58.5 & 2.04 \\
008 & $12,000.0$ & 336.0 & 80.7 & 35.5 & 31.2 & 39.5 & 33.7 & 31.6 & 29.2 & 52.1 & 2.01 \\
009 & $14,953.7$ & $1,965.2$ & 449.5 & 135.1 & 138.1 & 114.3 & 131.7 & 152.9 & 152.1 & 24.6 & 2.04 \\
010 & $11,204.7$ & 280.8 & 125.7 & 142.3 & 117.3 & 110.8 & 122.4 & 132.5 & 103.6 & 0.0 & 2.06 \\
\hline
\end{tabular}

5-FU, 5-fluoruracil; DPD, dihydropyrimidine dehydrogenase; U, uracil; UH2, dihydrouracil; DPD. Mild DPD deficiency was observed from $\mathrm{U}$ : UH2 fluctuation from 1.98-2.06.
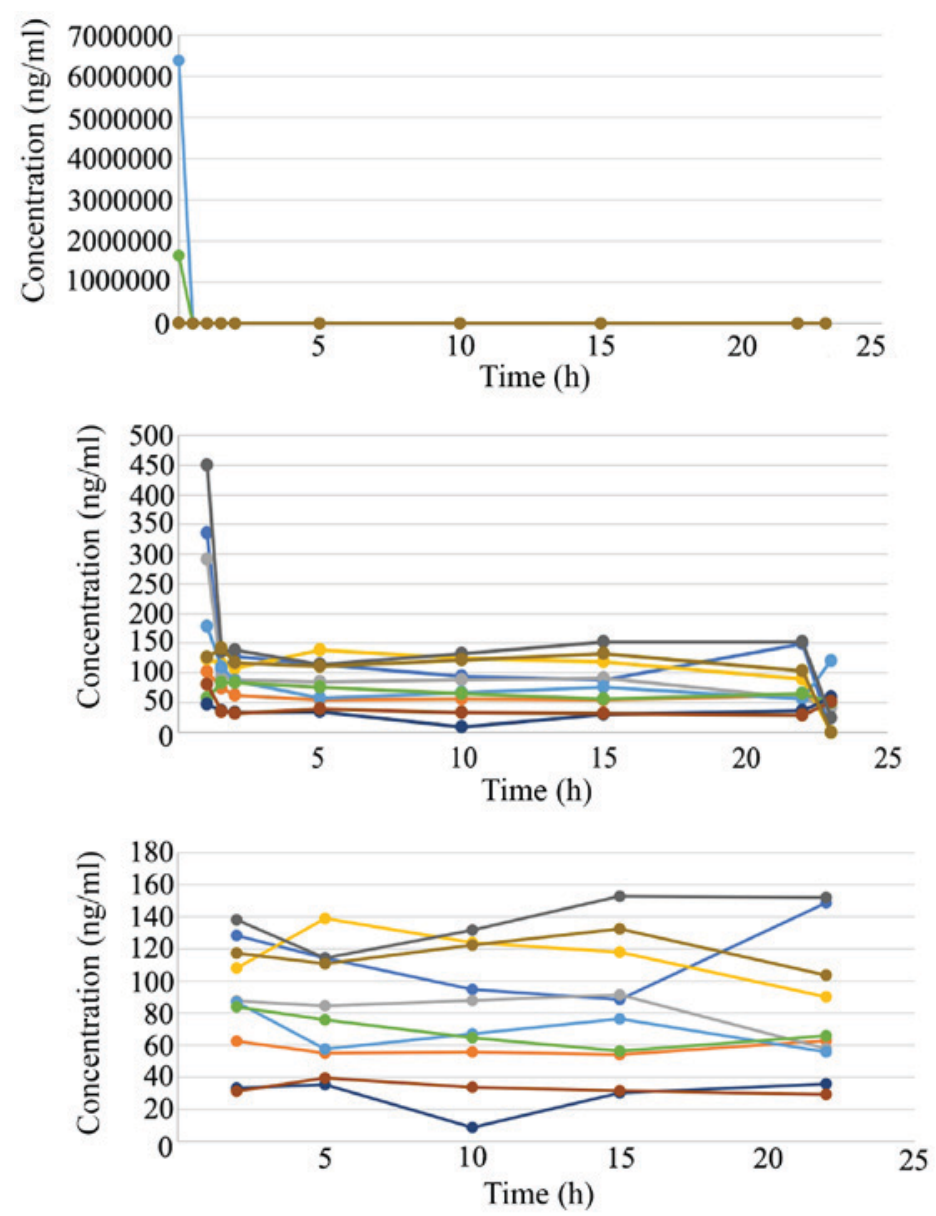

Patient ID:

$$
\begin{aligned}
& \rightarrow 001 \rightarrow 002 \\
& \rightarrow 003 \rightarrow 004 \\
& \rightarrow-005 \rightarrow 006 \\
& \rightarrow 007 \rightarrow 008 \\
& \rightarrow-009 \rightarrow 010
\end{aligned}
$$

Figure 3. Line charts showing 5-FU blood concentration (0-23 h). At $0 \mathrm{~h}$ of continuous infusion of 5-FU, 5-FU plasma concentration was markedly high compared with the normal range (200-300 ng/ml) due to previous 5-FU bolus, and subsequently declined rapidly. After 2 h, the concentration of 5-FU fluctuated mildly prior to reaching a steady state, and a steady plasma concentration was generally achieved after $15 \mathrm{~h}$ following administration through the hepatic artery. 5 -FU, 5-fluoruracil.

between 200-300 ng/ml in colorectal cancer (41-43). However, it is noteworthy that the comparisons between arterial and venous modes of administration, and between different types of cancer is insufficient. Therefore, the association between the steady-state concentration of 5-FU in peripheral blood and the efficacy of TACE + HAIC requires additional study. 
An additional notable result of the present study was that the concentration of 5-FU at $23 \mathrm{~h}$, which is the hour when 5-FU treatment was ceased, during the administration of folinic acid, exhibited various changes; 3 cases decreased to $0 \mathrm{ng} / \mathrm{ml}$, 4 decreased to a detectable degree $(24.6-49.4 \mathrm{ng} / \mathrm{ml})$ and 3 increased to more than the respective steady-state concentration (52.1-121.0 ng/ml). Folinic acid serves as a coactivator of thymidylate synthetase, which is the primary target of the continuous infusion action of 5-FU, to increase the efficacy of 5-FU (50). Rebound increases in the concentration of 5-FU during the administration of folinic acid were not expected at the initiation of the present study.

The present study contained several limitations. Firstly, the chemotherapy regimen used in the HAIC was FOLFOX4, which contains a chemotherapeutic agent-oxaliplatin. The anti-tumour role of oxaliplatin should not be neglected. Theoretically, the combination of 5-FU and oxaliplatin yielded additive or synergistic cytotoxic effects (51), but which one served the primary role remains unknown, and requires additional study. Also, the present study did not focus on the pharmacokinetics of oxaliplatin; the group are developing an assay that is simpler and more sensitive and cost-effective in clinical applications for quantitative assessment, although a small number of previous studies have described the use of laser ablation-inductively coupled plasma-mass spectrometry and flameless atomic absorption spectrometry methods $(52,53)$.

An additional limitation was that the prognosis of each patient was not completely assessed. A total of 3 of the 10 patients were lost to follow-up. However, the aim of the present study was not to assess the efficacy. There may be several prognostic factors of TACE + HAIC, including the materials used and extent of embolisation. The studies of Gao et al $(5,6)$ considered embolisation as the basis and core of combination therapy. Perfect embolisation may thoroughly block the blood supply of tumour and lower the risk of catheter malposition during chemotherapy (5). The present study only proposes an additional potential prognostic factor-the area under the curve of chemotherapeutic drugs. This is the basis for additional response evaluation and prognosis analysis.

To conclude, continuous transarterial infusion of 5-fluorouracil is a generally safe treatment. Optimised LC-MS may detect low concentrations of 5-FU. The steady-state concentration of 5-FU administered through the hepatic artery was achieved after $15 \mathrm{~h}$, which may provide a basis for additional therapeutic drug monitoring practice, response prediction and efficacy optimization.

\section{Competing interests}

The authors declare that they have no competing interests.

\section{References}

1. Bruix J and Sherman M; Practice Guidelines Committee, American Association for the Study of Liver Diseases: Management of hepatocellular carcinoma. Hepatology 42: 1208-1236, 2005.

2. Llovet JM and Bruix J: Systematic review of randomized trials for unresectable hepatocellular carcinoma: Chemoembolization improves survival. Hepatology 37: 429-442, 2003.

3. Llovet JM, Real MI, Montaña X, Planas R, Coll S, Aponte J, Ayuso C, Sala M, Muchart J, Solà R, et al: Arterial embolisation or chemoembolisation versus symptomatic treatment in patients with unresectable hepatocellular carcinoma: A randomised controlled trial. Lancet 359: 1734-1739, 2002.
4. Rammohan A, Sathyanesan J, Ramaswami S, Lakshmanan A, Senthil-Kumar P, Srinivasan UP, Ramasamy R and Ravichandran P: Embolization of liver tumors: Past, present and future. World J Radiol 4: 405-412, 2012.

5. Gao S, Zhu X, Yang R and Guo J: TACE combined with hepatic arterial infusion chemotherapy using oxaliplatin,5-fluorouracil and folinic acid for intermediate and advanced hepatocellular carcinomas. J Int Radiol 21: 377-383, 2012.

6. Gao S, Zhang PJ, Guo JH, Chen H, Xu HF, Liu P, Yang RJ and Zhu X: Chemoembolization alone vs combined chemoembolization and hepatic arterial infusion chemotherapy in inoperable hepatocellular carcinoma patients. World J Gastroenterol 21: 10443-1052, 2015.

7. Ishikawa M, Kakizawa H, Hieda M, Toyota N, Katamura Y, Aikata H, Chayama K and Awai K: Long-term outcomes of hepatic arterial port implantation using a coaxial microcatheter system in 176 patients with hepatocellular carcinoma. Hiroshima J Med Sci 61: 7-13, 2012.

8. Paul SB and Sharma H: Role of Transcatheter intra-arterial therapies for hepatocellular carcinoma. J Clin Exp Hepatol 4 (Suppl 3): S112-S121, 2014.

9. Obi S, Sato S and Kawai T: Current status of hepatic arterial infusion chemotherapy. Liver Cancer 4: 188-199, 2015.

10. Song MJ: Hepatic artery infusion chemotherapy for advanced hepatocellular carcinoma. World J Gastroenterol 21: 3843-3849, 2015.

11. Heidelberger C, Chaudhuri NK, Danneberg P, Mooren D, Griesbach L, Duschinsky R,Schnitzer RJ, Pleven E and Scheiner J: Fluorinated pyrimidines, a new class of tumour-inhibitory compounds. Nature 179: 663-666, 1957.

12. Milano G, Etienne MC, Cassuto-Viguier E, Thyss A, Santini J, Frenay M, Renee N, Schneider M and Demard F: Influence of sex and age on fluorouracil clearance. J Clin Oncol 10: 1171-1175, 1992.

13. Mueller F, Büchel B, Köberle D, Schürch S, Pfister B, Krähenbühl S, Froehlich TK, Largiader CR and Joerger M: Gender-specific elimination of continuous-infusional 5-fluorouracil in patients with gastrointestinal malignancies: Results from a prospective population pharmacokinetic study. Cancer Chemother Pharmacol 71: 361-370, 2013.

14. Diasio RB and Harris BE: Clinical pharmacology of 5-fluorouracil. Clin Pharmacokinet 16: 215-237, 1989.

15. Etienne MC, Lagrange JL, Dassonville O, Fleming R, Thyss A, Renée N, Schneider M, Demard F and Milano G: Population study of dihydropyrimidine dehydrogenase in cancer patients. J Clin Oncol 12: 2248-2253, 1994.

16. Lu Z, Zhang R and Diasio RB: Dihydropyrimidine dehydrogenase activity in human peripheral blood mononuclear cells and liver: Population characteristics, newly identified deficient patients, and clinical implication in 5-fluorouracil chemotherapy. Cancer Res 53: 5433-5438, 1993.

17. Sumie S, Yamashita F, Ando E, Tanaka M, Yano Y, Fukumori K and Sata M: Interventional radiology for advanced hepatocellular carcinoma: Comparison of hepatic artery infusion chemotherapy and transcatheter arterial lipiodol chemoembolization. AJR Am J Roentgenol 181: 1327-1334, 2003.

18. Monden M, Sakon M, Sakata Y, Ueda Y and Hashimura E; FAIT Research Group: 5-fluorouracil arterial infusion + interferon therapy for highly advanced hepatocellular carcinoma: A multicenter, randomized, phase II study. Hepatol Res 42: 150-165, 2012.

19. He MK, Le Y, Li QJ, Yu ZS, Li SH, Wei W, Guo RP and Shi M: Hepatic artery infusion chemotherapy using mFOLFOX versus transarterial chemoembolization for massive unresectable hepatocellular carcinoma: A prospective non-randomized study. Chin J Cancer 36: 83, 2017.

20. Chinese Society of Liver Cancer, Chinese Anti-Cancer Association; Chinese Society of Clinical Oncology, Chinese Anti-Cancer Association; Liver Cancer: Expert consensus on the scheme of pathological diagnosis of primary liver cancer. Zhonghua Gan Zang Bing Za Zhi 19: 254-256, 2011 (In Chinese).

21. Oken MM, Creech RH, Tormey DC, Horton J, Davis TE, McFadden ET and Carbone PP: Toxicity and response criteria of the Eastern Cooperative Oncology Group. Am J Clin Oncol 5: 649-655, 1982.

22. Pugh RN, Murray-Lyon IM, Dawson JL, Pietroni MC and Williams R: Transection of the oesophagus for bleeding oesophageal varices. Br J Surg 60: 646-649, 1973.

23. Forner A, Reig ME, de Lope CR and Bruix J: Current strategy for staging and treatment: The BCLC update and future prospects. Semin Liver Dis 30: 61-74, 2010. 
24. National Cancer Institute: Common Terminology Criteria for Adverse Events (CTCAE). NIH Publication, pp0-71, 2010.

25. Lencioni R and Llovet JM: Modified RECIST (mRECIST) Assessment for Hepatocellular Carcinoma. Semin Liver Dis 30: 52-60, 2010.

26. Seldinger SI: Catheter replacement of the needle in percutaneous arteriography; a new technique. Acta radiol 39: 368-376, 1953.

27. Remaud G, Boisdron-Celle M, Morel A and Gamelin A: Sensitive MS/MS-liquid chromatography assay for simultaneous determination of tegafur, 5-fluorouracil and 5-fluorodihydrouracil in plasma. J Chromatogr B Analyt Technol Biomed Life Sci 824: $153-160,2005$

28. Ishii H, Shimada M, Yamaguchi $\mathrm{H}$ and Mano N: A simultaneous determination method for 5-fluorouracil and its metabolites in human plasma with linear range adjusted by in-source collision-induced dissociation using hydrophilic interaction liquid chromatography-electrospray ionization-tandem mass spectrometry. Biomed Chromatogr 30: 1882-1886, 2016.

29. Peer CJ, McManus TJ, Hurwitz HI and Petros WP: Development and utilization of a combined LC-UV and LC-MS/MS method for the simultaneous analysis of tegafur and 5-fluorouracil in human plasma to support a phase I clinical study of oral UFT(R)/leucovorin. J Chromatogr B Analyt Technol Biomed Life Sci 898: 32-37, 2012.

30. Licea-Perez H, Wang S and Bowen C: Development of a sensitive and selective LC-MS/MS method for the determination of alpha-fluoro-beta-alanine, 5-fluorouracil and capecitabine in human plasma. J Chromatogr B Analyt Technol Biomed Life Sci 877: 1040-1046, 2009.

31. Büchel B, Rhyn P, Schürch S, Bühr C, Amstutz U and Largiadèr CR: LC-MS/MS method for simultaneous analysis of uracil, 5,6-dihydrouracil, 5-fluorouracil and 5-fluoro-5,6-dihydrouracil in human plasma for therapeutic drug monitoring and toxicity prediction in cancer patients. Biomed Chromatogr 27: 7-16, 2013.

32. Kosovec JE, Egorin MJ, Gjurich S and Beumer JH: Quantitation of 5-fluorouracil (5-FU) in human plasma by liquid chromatography/electrospray ionization tandem mass spectrometry. Rapid Commun Mass Spectrom 22: 224-230, 2008.

33. Carli D, Honorat M, Cohen S, Megherbi M, Vignal B, Dumontet C, Payen L and Guitton J: Simultaneous quantification of 5-FU, 5-FUrd, 5-FdUrd, 5-FdUMP, dUMP and TMP in cultured cell models by LC-MS/MS. J Chromatogr B Analyt Technol Biomed Life Sci 877: 2937-2944, 2009.

34. Boisdron-Celle M, Remaud G, Traore S, Poirier AL, Gamelin L, Morel A and Gamelin E: 5-Fluorouracil-related severe toxicity: A comparison of different methods for the pretherapeutic detection of dihydropyrimidine dehydrogenase deficiency. Cancer Lett 249: 271-282, 2007.

35. Garg MB, Sevester JC, Sakoff JA and Ackland SP: Simple liquid chromatographic method for the determination of uracil and dihydrouracil plasma levels: A potential pretreatment predictor of 5-fluorouracil toxicity. J Chromatogr B Analyt Technol Biomed Life Sci 774: 223-230, 2002.

36. Jiang $\mathrm{H}$, Jiang J, $\mathrm{Hu} \mathrm{P}$ and $\mathrm{Hu} \mathrm{Y}$ : Measurement of endogenous uracil and dihydrouracil in plasma and urine of normal subjects by liquid chromatography-tandem mass spectrometry. J Chromatogr B Analyt Technol Biomed Life Sci 769: 169-176, 2002.

37. Jiang H, Lu J and Ji J: Circadian rhythm of dihydrouracil/uracil ratios in biological fluids: A potential biomarker for dihydropyrimidine dehydrogenase levels. Br J Pharmacol 141: 616-623, 2004.

38. Ben Fredj R, Gross E, Ben Ahmed S, Hassine H and Saguem S: The dihydrouracil/uracil ratio in plasma, clinical and genetic analysis for screening of dihydropyrimidine dehydrogenase deficiency in colorectal cancer patients treated with 5-fluorouracil. Pathol Biol (Paris) 57: 470-476, 2009.

39. Gamelin E, Boisdron-Celle M, Guérin-Meyer V, Delva R, Lortholary A, Genevieve F, Larra F, Ifrah N and Robert J: Correlation between uracil and dihydrouracil plasma ratio, fluorouracil (5-FU) pharmacokinetic parameters, and tolerance in patients with advanced colorectal cancer: A potential interest for predicting 5-FU toxicity and determining optimal 5-FU dosage. J Clin Oncol 17: 1105, 1999.
40. Ciccolini J, Mercier C, Evrard A, Dahan L, Boyer JC, Duffaud F, Richard K, Blanquicett C, Milano G, Blesius A, et al: A rapid and inexpensive method for anticipating severe toxicity to fluorouracil and fluorouracil-based chemotherapy. Ther Drug Monit 28: 678-685, 2006.

41. Seitz JF, Cano JP, Rigault JP, Aubert C and Carcassonne Y: Chemotherapy of extensive digestive cancers with 5-fluorouracil: Relation between the clinical response and plasma clearance of the drug. Gastroenterol Clin Biol 7: 374-380, 1983 (In French).

42. Gamelin EC, Danquechin-Dorval EM, Dumesnil YF, Maillart PJ, Goudier MJ, Burtin PC, Delva RG, Lortholary AH, Gesta PH and Larra FG: Relationship between 5-fluorouracil (5-FU) dose intensity and therapeutic response in patients with advanced colorectal cancer receiving infusional therapy containing 5-FU. Cancer 77: 441-451, 1996.

43. Gamelin E, Delva R, Jacob J, Merrouche Y, Raoul JL, Pezet D, Dorval E, Piot G, Morel A and Boisdron-Celle M: Individual fluorouracil dose adjustment based on pharmacokinetic follow-up compared with conventional dosage: Results of a multicenter randomized trial of patients with metastatic colorectal cancer. J Clin Oncol 26: 2099-2105, 2008.

44. Alanazi FK, Yassin AE, El-Badry M, Mowafy HA and Alsarra IA: Validated high-performance liquid chromatographic technique for determination of 5-fluorouracil: Applications to stability studies and simulated colonic media. J Chromatogr Sci 47: 558-563, 2009.

45. Serve KM, Yáñez JA, Remsberg CM, Davies NM and Black ME: Development and validation of a rapid and sensitive HPLC method for the quantification of 5-fluorocytosine and its metabolites. Biomed Chromatogr 24: 556-561, 2010.

46. Licea-Perez H, Wang S and Bowen C: Development of a sensitive and selective LC-MS/MS method for the determination of alpha-fluoro-beta-alanine, 5-fluorouracil and capecitabine in human plasma. J Chromatogr B Analyt Technol Biomed Life Sci 877: 1040-1046, 2009.

47. Blaschke M, Blumberg J, Wegner U, Nischwitz, M, Ramadori, G and Cameron S: Measurements of 5-FU plasma concentrations in patients with gastrointestinal cancer: 5 -FU levels reflect the 5-FU dose applied. J Cancer Ther 3: 28-36, 2012.

48. Jianshi L: Pharmacology [M]: Tsinghua University Press 3 . 20-21, 2015.

49. Kaldate RR, Haregewoin A, Grier CE, Hamilton SA and McLeod HL: Modeling the 5-fluorouracil area under the curve versus dose relationship to develop a pharmacokinetic dosing algorithm for colorectal cancer patients receiving FOLFOX6. Oncologist 17: 296-302, 2012.

50. Machover D, Goldschmidt E, Chollet P, Metzger G, Zittoun J, Marquet J, Vandenbulcke JM, Misset JL, Schwarzenberg L, Fourtillan JB, et al: Treatment of advanced colorectal and gastric adenocarcinomas with 5-fluorouracil and high-dose folinic acid. J Clin Oncol 4: 685-696, 1986.

51. Raymond E, Faivre S, Chaney S, Woynarowski J and Cvitkovic E: Cellular and molecular pharmacology of oxaliplatin. Mol Cancer Ther 1: 227-235, 2002

52. Moraleja I, Esteban-Fernández D, Lázaro A, Humanes B, Neumann B, Tejedor A, Luz Mena M, Jakubowski N and Gómez-Gómez MM: Printing metal-spiked inks for LA-ICP-MS bioimaging internal standardization: Comparison of the different nephrotoxic behavior of cisplatin, carboplatin, and oxaliplatin. Anal Bioanal Chem 408: 2309-2318, 2016.

53. LeRoy AF, Wehling ML, Sponseller HL, Friauf WS, Solomon RE, Dedrick RL, Litterst CL, Gram TE, Guarino AM and Becker DA: Analysis of platinum in biological materials by flameless atomic absorption spectrophotometry. Biochem Med 18: 184-191, 1977.

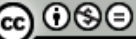

This work is licensed under a Creative Commons Attribution-NonCommercial-NoDerivatives 4.0 International (CC BY-NC-ND 4.0) License. 